\title{
Pain Management for the Terminally Ill: The Role of Race and Religion
}

Article DOI: http://dx.doi.org/10.5915/43-3-9039

Video DOI: http://dx.doi.org/10.5915/43-3-9039v

\author{
Cheryl Mwaria, PhD \\ Professor of Anthropology \\ Hofstra University \\ Hempstead, New York
}

$\mathrm{P}$ ain management is a primary concern of both patients facing terminal illness and their loved ones. Pain itself is known to be both a universal and a very personal experience. Given the private nature of pain, the individual must express it in order to make it known. The expression of pain and its companion, suffering, are subjective and heavily influenced by one's culture. The clinical and social manifestations of pain and suffering are varied as numerous anthropological studies have shown. ${ }^{1}$

Psychologist Lisa Stepp describes pain as follows:

Pain can be classified into two distinct temporal categories: acute pain, which lasts fewer than 30 days and can be seen as beneficial in that it provides a warning of underlying bodily damage, and chronic pain which lasts more than one month as is often the case for those with terminal illness. The exception to the temporal component is seen when the underlying cause of pain is untreatable. In those cases, patients should be treated for chronic pain. The characteristics of chronic pain are detrimental to the quality of life. The goal of chronic pain management is therefore, avoidance. Consequently, physicians generally order scheduled pain medication as opposed to promoting taking medication "as needed" for chronic pain sufferers. ${ }^{2}$

As Stepp" argues, "Substantial evidence indicates that neither acute nor chronic pain are [sic] managed adequately within most U.S. health-care sys-

Correspondence should be directed to

Cheryl Mwaria, PhD

Cheryl.B.Mwaria@hofstra.edu tems. If treated by using acute pain process strategies, chronic pain may become more intense, with the patient experiencing increased disability and suffering." Chronic pain requires both physical and psychological strategies for proper management given its accompanying component of suffering. Suffering may include any or all of the following symptoms: sadness, anger, loneliness, depression, grief, unhappiness, melancholy, rage, withdrawal, yearning, powerlessness, helplessness and hopelessness, isolation and unremitting fear. ${ }^{2}$ The Agency for Health Care Policy and Research (now the Agency for Healthcare Research and Quality) published guidelines in 1994 for the management of cancer pain, which identified four areas of quality of life that are affected by pain: physical, psychological, social, and spiritual. ${ }^{3}$ This is clear in clinical settings in that the primary question relatives ask following a patient's death is "Did he or she suffer?" The invariable answer to this is "No" regardless of the circumstances, and relatives and loved ones accept it.

Even a brief review of the literature suggests that race and religion play a critical role in the management of pain for the terminally ill in the United States and that they may do so for both patients and medical practitioners. Despite the publication of clear guidelines for cancer pain management and for palliative care, a review of the medical literature indicates that significant barriers remain for optimal end-of-life care, particularly for minority patients. After observing that "many black and Hispanic patients receiving palliative care at a major urban teaching hospital are unable to obtain prescribed opioids from their neighborhood pharmacies," Morrison et al surveyed a random sample of $30 \%$ of New York City pharmacies and found that "pharmacies in predominantly nonwhite neighborhoods do not stock sufficient medications to treat patients 
with severe pain adequately." 4 Pletcher et al found that "opioid prescribing for patients making a painrelated visit to the emergency department increased after national quality improvement initiatives in the late 1990s, but differences in opioid prescribing by race or ethnicity have not diminished."' In two separate studies, Todd et al found that Hispanics with isolated long-bone fractures are twice as likely as nonHispanic Caucasians to receive no pain medication in the University of California, Los Angeles (UCLA) Emergency Center ${ }^{6}$ and that African-American patients were less likely than Caucasian patients to receive analgesics in the same emergency department. ${ }^{7}$ Cleeland et al found that clinics that primarily serve members of ethnic minority groups provide inadequate treatment for cancer-related pain. ${ }^{8}$ These studies and others like them attest to the enduring "unequal access" affirmed by the Institute of Medicine's landmark study Unequal Treatment: Confronting Racial and Ethnic Disparities in Health Care. ${ }^{9}$

What are the wishes of minority patients with respect to end-of-life care? We know that AfricanAmericans are more likely than Caucasians to die in the hospital and to prefer intensive treatment near the end of life.10-12 The same study found that "even those with a more clinically realistic estimation of the effectiveness of mechanical ventilation, blacks were twice as likely as Hispanics and non-Hispanic whites to want a ventilator for life extension of one month or one week."10 Cykert et al found that African-Americans had a greater preference than Caucasians to remain alive in spite of severe disability. ${ }^{13}$ Research comparing African-Americans to Caucasians has found that fewer hospitalized African-Americans have do-not-resuscitate (DNR) directives ${ }^{14-18}$ and receive more cardiopulmonary resuscitation (CPR) than do Caucasians. ${ }^{19}$ AfricanAmericans have fewer advance directives and living wills ${ }^{20-22}$ and even believe they may receive less care with a living will. ${ }^{23}$ Pritchard et al found that although most patients prefer to die at home, and whether they die in the hospital is influenced by "characteristics of the local health system." 24 One study found that $62 \%$ of the African-Americans surveyed would prefer to die in the hospital. ${ }^{25}$ These findings are somewhat surprising in that they do not conform with mainstream American cultural views of a "good death," which some terminal illnesses, particularly some forms of cancer, seem to allow. The Institute of Medicine's Committee on Care at the End of Life defines a good death as one that is "free from avoidable distress and suffering for patients, families, and caregivers; in accord with the patients' and families' wishes; and reasonably consistent with clinical, cultural, and ethical standards. A bad death, in turn, is one that is characterized by needless suffering, dishonoring of patient and family wishes or values, and a sense among participants or observers that norms of decency have been offended. Bad deaths include those resulting from or accompanied by neglect, violence, or unwanted and senseless medical treatments." ${ }^{26}$ While Americans may agree on these definitions, anyone bearing witness to the long process of dying from a terminal illness knows that death is often neither quick nor peaceful regardless of the setting.

The influence of religion on coping with pain and terminal illness in the United States is varied and complex in that religious beliefs themselves are varied and can be interpreted quite differently from one individual to the next. Religious practice, too, in the form of prayer, meditation, and religious study vary greatly within any given population. Balboni et al. in a recent multicentered study found that 885 members of the study population considered religion to be at least somewhat important but did not feel their spiritual needs were supported by either religious communities or the medical system, although spiritual support was associated with a better quality of life. ${ }^{27}$ In this study and others, "higher levels of religiousness were found to be associated with wanting all measures to extend life." 28 Another multisite study led by Phelps et al. distinguished religious coping, the way a patient makes use of his or her religious beliefs to understand and adapt to stress, from more general measures of religiousness and concluded that in patients with advanced cancer, positive religious coping was associated with receipt of intensive life-prolonging medical care near death. ${ }^{29}$ Negative religious coping, such as viewing illness as divine punishment, has been associated with psychological crises. ${ }^{30-32}$ These studies are surprising in that Americans generally assume that health-care professionals, having voluntarily chosen to enter a "helping" profession, would not discriminate against individuals or groups. Indeed most patients, even members of minority groups, trust their individual 
doctors even when they are mistrustful of the "system." 33 Americans also assumed that "religious" people would prefer to approach the end of life in a hospice or home setting with hospice rather than opt for high tech end-of-life interventions. Neither of these assumptions appears to be true. The challenge is in understanding why we have to consider race and religion as aspects of culture.

Though our current scientific approach to death in the United States, focusing as it does on the individual, seems to presume culture is irrelevant, nothing could be further from the truth. Anthropologists know that culture, which is learned behavior, though not always consciously learned, socializes members of any given society to view the world in a particular way even before they are aware of it. It blinds us to some of our behaviors, making us believe they are perfectly natural, rather than a product of our socialization to a given cultural perspective. For instance, as Americans, we are attached to the notion of individualism, that the interests of the individual are primary and that the success or failure of individual accomplishments is the sole responsibility of the individual. As John Hartigan has so clearly articulated, "Part of this denial stems from our strong belief in individualism: that group circumstances are shaped by social inequality flies in the face of the ideal that we are all equal as individuals." 34 This core belief has had a profound impact on the way Americans, even many African-Americans, see race. While most Americans deplore racism as an individual failing, they fail to see the structurally embedded racism in our society. It is this same structural racism that leads to differential access to pain medication based on race or ethnicity. Ethnographic data suggests Americans, at least traditionally, favored a stoic attitude toward pain. It is the history and experience of embedded racism that leads many minorities to eschew advanced directives and insist that maximum medical intervention be provided at the-end-of-life. This was particularly true of AfricanAmericans, hence, the quote at the beginning of this paper.

According to a recent Pew poll, "[c]ompared with other racial and ethnic groups, African-Americans are among the most likely to report a formal religious affiliation, with fully $87 \%$ of African-Americans describing themselves as belonging to one religious group or another, according to the U.S. Religious
Landscape Survey, conducted in 2007 by the Pew Research Center's Forum on Religion \& Public Life. Latinos also report affiliating with a religion at a similarly high rate of $85 \%$; among the public overall, $83 \%$ are affiliated with a religion. The Landscape Survey also finds that nearly eight-in-ten AfricanAmericans (79\%) say religion is very important in their lives, compared with $56 \%$ among all U.S. adults. In fact, even a large majority (72\%) of AfricanAmericans who are unaffiliated with any particular faith say religion plays at least a somewhat important role in their lives; nearly half $(45 \%)$ of unaffiliated African-Americans say religion is very important in their lives, roughly three times the percentage who says this among the religiously unaffiliated population overall (16\%). Indeed, on this measure, unaffiliated African-Americans more closely resemble the overall population of Catholics (56\% say religion is very important) and mainline Protestants (52\%)." 35

This religiosity has historical roots dating to the arrival of blacks in the 17th century and their adaptation of Christianity to their own needs and to the religious perspectives they brought from Africa. Anthropologists Sidney Mintz and Richard Price opined, "...most West African and Central African religions seem to have shared certain fundamental assumptions about the nature of causality and the ability of divination to reveal specific causes, about the active role of the dead in the lives of the living, about the responsiveness of (most) deities to human actions, about the close relationship between social conflict and illness or misfortune, and many others." 36 Historian Leon Litwick notes, "Drawing from history, life experiences, and theology, ministers preached both a biblical and pragmatic gospel. The sermon often revolved around depictions of the afterlife, proximity to God, atonement on the cross, and the duties and responsibilities that fell to parishioners to reform their lives and stay in the straight path... . Although the emphasis varied from church to church, much of the impassioned oratory from the pulpit was reserved for examining prospects in the afterlife." 37 This admonition to live a morally sound life or face the wrath of God, whether in the immediate or afterlife, is synonymous with a negative coping strategy, every bit as much as belief in God's ability to make all pain bearable and reward one with a heavenly afterlife is a positive coping strategy. The vast number of African-Americans are Protestant 
Christians, but even those who embrace other religions use both positive and negative coping strategies that affect their medical decision-making. This is not to embrace the 19th century abolitionists' claim that African-Americans were innately religious or moral but to argue that African-American religious perspectives and practices were and are both malleable and adaptive. Thus their current embrace of medical intervention at the end-of-life may be a response to embedded racism, rather than a symbol of lack of faith.

The hidden belief in individualism may play a role here too in that patients fear becoming burdens to their loved ones. They may also be unaware of the support that both palliative care and a hospice setting provide. On the other hand, in the absence of training and material support, family members may feel inadequate to provide the technical support the patient needs. Any discussion of pain management and medical decision-making in the context of terminal illness should consider the cultural context in which such decisions are made. This is particularly so in race and ethnic-based societies. Focus groups and surveys can easily mask deep-rooted cultural biases at the heart of such decisions and obscure the history and cultural context in which such decisions are made. An ethnographic analysis grounded in such a cultural context is capable of providing far more insight.

\section{References}

1. Good BJ, Good MD. The meaning of symptoms: a cultural hermeneutic model for clinical practice. In: Eisenberg L, Kleinman A, editors. The relevance of social science for medicine. Boston: D. Reidel; 1981: 165-96.

2. Stepp L. A psychologist's view of pain and suffering. In: Iyer PW, editor. Medical-legal aspects of pain and suffering. Tucson: Lawyers and Judges Pub.; 2003: 69-89.

3. Management of cancer pain guideline overview. Agency for Health Care Policy and Research Rockville, Maryland. J Natl Med Assoc. 1994; 86:5713, 634. PubMed PMID: 7932833

4. Morrison RS, Wallenstein S, Natale DK, et al. "We don't carry that"- failure of pharmacies in predominantly nonwhite neighborhoods to stock opioid analgesics. N Engl J Med. 2000;342:1023-6. http://dx.doi.org/10.1056/NEJM200004063421406
5. Pletcher MJ, Kertesz SG, Kohn MA, et al. Trends in opioid prescribing by race/ethnicity for patients seeking care in US emergency departments. JAMA. 2008;299:70-8. http://doi.org/hg3

6. Todd KH, Samaroo N, Hoffman JR. Ethnicity as a risk factor for inadequate emergency department analgesia. JAMA. 1993;269:1537-9. http://doi.org/ hg4

7. Todd KH, Deaton C, D'Adamo AP, et al. Ethnicity and analgesic practice. Ann Emerg Med. 2000;35:116. http://dx.doi.org/10.1016/S0196-0644(00)70099-0 8. Cleeland CS, Gonin R, Baez L, et al. Pain and treatment of pain in minority patients with cancer. The Eastern Cooperative Oncology Group Minority Outpatient Pain Study. Ann Intern Med. 1997;1279:813-6. PubMed PMID: 9382402

9. Smedley BD, Stith AY, Nelson AR, editors. Unequal Treatment: Confronting Racial and Ethnic Disparities in Health Care. Washington, D.C.: National Academy Press; 2003.

10. Barnato AE, Anthony DL, Skinner J, et al. Racial and ethnic differences in preferences for end-of-life treatment. J Gen Intern Med. 24:695-701. http://dx.doi.org/10.1007/s11606-009-0952-6

11. Garrett JM, Harris RP, Norburn JK, et al. Life-sustaining treatments during terminal illness: Who wants what? J Gen Intern Med. 1993;8:361-8. http://dx.doi.org/10.1007/BF02600073

12. Gramelspacher GP, Zhou XH, Hanna MP, et al. Preferences of physicians and their patients for endof-life care. J Gen Intern Med. 1997;12:346-51. http://dx.doi.org/10.1007/s11606-006-5082-9 13. Cykert S, Joines JD, Kissling G, et al. Racial differences in patients' perceptions of debilitated health states. J Gen Intern Med. 1999;14:217-22. http://dx.doi.org/10.1046/j.1525-1497.1999.00320.x

14. Beach MC, Morrison RS. The effect of do-notresuscitate orders on physician decision-making. J Am Geriatr Soc. 2002;50:2057-61. http://doi.org/hg5 15. Blackhall LJ, Frank G, Murphy ST, et al. Ethnicity and attitudes towards life-sustaining technology. Soc Sci Med. 1999;48:1779-89. http://doi.org/hg6

16. McKinley ED, Garrett JM, Evans AT, et al. Differences in end-of-life decision making among black and white ambulatory cancer patients. J Gen Intern Med. 1996;11:651-6.http://doi.org/bvtm24 17. Murphy ST, Palmer JM, Azen S, et al. Ethnicity and advance care directives. J Law Med Ethics. 1996;24:108-17.http://doi.org/hg7 
18. Hofmann JC, Wenger NS, Davis RB, et al. Patient preferences for communication with physicians about end-of-life decisions. SUPPORT Investigators. Study to Understand Prognoses and Preference for Outcomes and Risks of Treatment. Ann Intern Med. 1997;127:1-12. PubMed PMID: 9214246

19. Goodlin SJ, Zhong Z, Lynn J, et al. Factors associated with use of cardiopulmonary resuscitation in seriously ill hospitalized adults. JAMA. 1999;282:2333-39. http://doi.org/hg8

20. Emanuel EJ, Fairclough DL, Slutsman J, et al. Understanding economic and other burdens of terminal illness: The experience of patients and their caregivers. Ann Intern Med. 2000;132:451-9. PubMed PMID: 10733444

21. Eleazer GP, Hornung CA, Egbert CB, et al. The relationship between ethnicity and advance directives in a frail older population. J Am Geriatr Soc. 1996;44:155-65.

22. Hanson LC, Rodgman E. The use of living wills at the end of life. A national study. Arch Intern Med. 1996;156:1018-22. PubMed PMID: 8624167

23. Caralis PV, Davis B, Wright K, et al. The influence of ethnicity and race on attitudes toward advance directives, life prolonging treatments, and euthanasia. J Clin Ethics. 1993;4:155-65. PubMed PMid: 8334279

24. Pritchard RS, Fisher ES, Teno JM, et al. Influence of patient preferences and local health system characteristics on the place of death. SUPPORT Investigators. Study to Understand Prognoses and Preferences for Risks and Outcomes of Treatment. J Am Geriatr Soc. 1998;46:1242-50. PubMed PMID: 9777906

25. Neubauer BJ, Hamilton CL. Racial differences in attitudes toward hospice care. Hosp J. 1990;6:37-48. PubMed PMID: 2379922

26. Committee on Care at the End of Life, Institute of Medicine. Approaching death: Improving care at the end of life. Field MJ, Cassel CK, editors. Washington, D.C.: The National Academies Press; 1997. http://www.nap.edu/catalog.php?record $\mathrm{id}=5801$ 27. Balboni TA, Vanderwerker LC, Block SD, et al. Religiousness and spiritual support among advanced cancer patients and associations with end-of-life treatment preferences and quality of life. J Clin Oncol. 2007;25:555-60. http://doi.org/hg9

28. True G, Phipps EJ, Braitman LE, et. al Treatment preferences and advance care planning at end of life:
The role of ethnicity and spiritual coping in cancer patients. Ann Behav Med. 2005;30:174-9. http://doi.org/bdgvqc

29. Phelps AC, Maciejewski PK, Nilsson M, et al. Religious coping and use of intensive life-prolonging care near death in patients with advanced cancer. JAMA. 2009;301:1140-7.http://doi.org/hhb

30. Ano GG, Vasconcelles EB. Religious coping and psychological adjustment to stress: a meta-analysis. J Clin Psychol. 2005;61:461-80.http://doi.org/hhc

31. Pargament KI, Koenig HG, Tarakeshwar N, et al. Religious struggle as a predictor of mortality among medically ill elderly patients: a 2 year longitudinal study. Arch Intern Med. 2001;161:1881-5. http://dx.doi.org/10.1001/archinte.161.15.1881

32. Pargament KI, Zinnbauer BJ, Scott AB, et al. Red flags and religious coping: identifying some religious warning signs among people in crisis. J Clin Psychol. 1998;54:77-89. http://doi.org/gqx

33. Mwaria C. From conspiracy theories to clinical trials: questioning the role of race and culture versus racism and poverty in medical decision making. In: AJ, Mullings L, editors. Gender, race, class \& health: intersectional approaches. San Francisco: JosseyBass; 2006: 289-312.

34. Hartigan JJR. Race in the 21st century: ethnographic approaches. New York: Oxford University Press; 2010.

35. Sahgal N, Smith G. A religious portrait of AfricanAmericans. Washington, D.C.: The Pew Forum on Religion \& Public Life. http://pewforum.org/AReligious-Portrait-of-African-Americans.aspx [Updated 2009 Jan 30; Accessed 2011 Nov 17]

36. Mintz SW, Price R. The birth of African-American culture: an anthropological perspective. Boston: Beacon American Press; 1992.

37. Litwack LF. Trouble in mind: black southerners in the age of Jim Crow. New York: Vintage Books; 1998.

\section{Question from the audience:}

Dr. Jameel Khan: Most of the racial biases are rooted in human creationism. There are two varieties: biblical and hinduic variety in India. In both systems, we have an inferior race -- children of ham, are being told, that your children will ever serve the progeny of the other two children, who are Jafit and Shem. Same thing happens in India. In other words, certain principles of creationism, the Bible and the Torah, sort of mandate slavery. Fortunately for good 
or bad, in the Muslim holy book, the Qur'an, this is nonexistent. There is no racial biases. There is slavery in Islam, but that slavery is an economic-based slavery. It is color blind. Thank you very much for eliminating this.

Dr. Mwaria's response: I did not really want to say that the racism was religiously grounded. I wanted to say that it was culturally grounded, and that is a slightly different perspective. We are all socialized to given cultural beliefs and, though they are learned, we are not generally aware when we are learning them. They really do color the way we look at the world. In fact they color the way we see end of life. They certainly color the way we as a society are going to go about resolving some of these issues.

Dr. Shahid Athar: Is there any distrust of physicians, especially Caucasian physicians by minorities? Is it a lack of communication or a lack of resources?

Dr. Mwaria's response: The research seems to show, even my own work in a clinical trial setting, that patients do not mistrust their individual physicians even when those physicians are not so good. They tend to trust their individual physicians, but they tend not to trust the system. Many members of minorities in our culture are also poor as a result of that same embedded racism that we tend to ignore or are blind to. Most such people do not have a single physician or internist that has worked with them over the years. Instead, they generally present first in the emergency room. That is the baseline defense for most poor people, and certainly minorities. Under those conditions, it is very unlikely that they have established a bond of trust with whosever they find there because the personnel change all the time. It is very unlikely that someone is going to meet the same physician over the course of his or her medical treatment. And I would like to say one other thing here, and this will be in defense of physicians. Most clinicians have a heavy case load, and generally they can only spend a very brief period with each patient. My research in a cancer hospital showed, that, in the clinic, physicians had roughly 5-7 minutes per patient. Under those conditions, it is really hard to build a bond, and, in fact, I would say it is why often the option of palliative care is left to the nurse prac- titioner or someone else. I do want to say though there is that hidden history.

\section{Question from the audience:}

I am going to make two comments. I was quite involved in the Haiti project. After the disaster, in the hospitals when there were medical services provided from all over the world, the most important thing from the Haitians' perspective in the hospital wards was the prayers, not the medicines or the procedures. Not only that, according to their customs, when the relatives would come to the hospital, they would do their prayers and chanting, and often the doctors would also join them. The second comment regards an HIV prevention program in one of the western African countries where there was a lot of reluctance to distribute condoms. The program was divided into three phases. The first phase was group prayer to overcome their moral weakness and abstain from sex. The second phase would be support from the medical personnel and family. If these do not work, then they will be given condoms. Living here and having practiced for some 30 years, I could not understand. My question to the professor is, at one point, you mentioned a lot of things like anger, anxiety, which are all psychological, and which is very understandable from someone who is suffering from a terminal illness. Does the research show that a part of those psychological symptoms is somehow based on medical, physical, and biological factors? Thank you very much.

Dr. Mwaria's response: Well what I said was that those symptoms, although they are psychological, were the result of being in the state of chronic pain. Chronic pain of course can bring about many, many different responses, certainly those psychological ones among them. So my answer to you would be that, yes, there is a biological component to that.

Dr. Hasan Shanawani: I am an intensivist who practices at a cancer center in Detroit where about $80 \%$ of our population is inner city black, elderly people, and what we have observed is that there is a lot of issues among the ones that you have mentioned with literacy, numeracy, ability to bring a second person to the clinic, a third person to act as a quality check on the conversation between the physician and the patient. Often they can not bring 
that second person because that second person is a hourly wage earner so they cannot take the time off. What we are seeing in observed clinical interactions between physicians and patients is that there is a huge cultural gap that we seem unable to bridge. The majority of our physicians are international medical graduates. They do not know much about American culture, much less inner city Detroit culture. Even as an American medical graduate, I do not know much about inner city Detroit culture, and so I find myself working on a lot of things. We have this great videotaped interaction where a patient is talking with a south Asian physician. The physician says, "I am Indian." The patient is thinking native American, the physician is thinking south Asian, and you can see this exchange that goes. It is sort of an Abbott and Costello "Who's on first?" skit, which is funny, except for the fact that it is not. And so just on a practical level, you have only five minutes. I am often inheriting patients who have been taken care of for five months by a number of people in my practice. In inpatient care, between five and ten physicians are taking care of each patient. So there is no trust of the physician. I mean that the one doctor who has been taking care of you for weeks or months, you may not see them at your darkest hour. I have never met those patients until they are on the tail end of a debilitating, ultimately terminal illness. So what are your thoughts about this? How do you bridge that in five minutes or less, or do you just say we cannot?

Dr. Mwaria's response: Well, I hate to be completely pessimistic. I know that some hospitals in New York have patient navigators, people who serve particularly for the poor as a kind of liaison between the physician and the patient, and that is one way. I think that patients, as well as physicians, can continue to be educated as to what their rights are, what to expect, and to understand, again, that what we are seeing is not a matter of physicians' themselves being, necessarily, overtly racist or not wanting to see their patients in the best light. I think the educational part of that has to be two ways. But we are on an uphill climb. We are a very heterogeneous society, that is wonderful, and we are increasingly so. I think what you are experiencing is what we call the intersectionality of race, class, gender, etc. Each of those components can kind of work synergistically to provide even more complications, more inability to understand one another.

Dr. Hasan Shanawani: There is a wonderful article that just came out 3 weeks ago by Randy Curtis where they did a multi-center trial on physician education to improve end-of-life care. It did not work. The current data says you cannot educate physicians, and it is easier to educate one doctor than 100 patients, so I am not sure that will work.

Dr. Mwaria's response: I am not sure we can educate our physicians either. Here at Hofstra one of the things the dean of our medical school wants to do is to have nurses trained with physicians just so that lack of communication can be overcome. I know there is a lot of training in young physicians, a lot of things poured in, but I think we can at least help people see the hidden assumptions that we all bring to the table. Thank you. 